\title{
HISTOPATHOLOGICAL STUDY OF UTERINE LESIONS IN HYSTERECTOMY SPECIMENS IN A TERTIARY CARE HOSPITAL.
}

\section{Pathology \\ Dr Reddythota Sujeeva Swapna \\ MD Associate Professor Of Pathology, Government Medical College, Anantapur, Andhrapradesh 515001.}

\section{Dr V Siva Sankar} Naik*

\section{Dr C Bhavani}

\section{Dr M Neeraja}

MD, Associate Professor Of Pathology, Government Medical College, Anantapur, Andhrapradesh 515001. *Corresponding Author.

MD Associate Professor Of Pathology, Government Medical College, Anantapur, Andhrapradesh 515001.

MD Professor And Head, Department Of Pathology, Government Medical College, Anantapur, Andhrapradesh 515001.

\section{ABSTRACT}

Background: The Female Genital Tract is a hormone-responsive system to a degree unmatched by any other system in the body. The gross configuration of the uterus changes dramatically throughout life. It is a kind of 'Puppet on a string", thus manipulated throughout life by altering levels of ovarian hormones.

Objective of the study: The present study is aimed at detailed histopathological evaluation of uterine lesions of hysterectomy specimens.

Methodology: A total of 448 cases of hysterectomy specimens were received in the department of pathology GGH Ananthapur, for two years, were reviewed. The specimens were processed, and the histopathological diagnosis was studied.

Result: Peak age group of hysterectomy was 40-49 years with $186(41.51 \%)$ cases. The youngest patient was 21 years old, and the oldest was 75 years old. The most frequent type of hysterectomy done was total abdominal hysterectomy in $293(65.4 \%)$ cases.

Conclusion: Hysterectomy is the most common surgery performed in gynecological practice. A wide range of lesions were noted when hysterectomy specimens are subjected to histopathological examination.

\section{KEYWORDS}

Hysterectomy, Histopathology.

\section{INTRODUCTION}

The female reproductive system has been affected by various abnormalities and diseases. Hence this has been the subject of interest and the basis for the gynecological practice. The uterus consists of the endometrium and myometrium, continuously stimulated by hormones, denuded monthly of its endometrial mucosa, and inhabited periodically by fetuses. (1) The uterus is a vital reproductive, and hormone-responsive organ is subjected to a variety of physiological changes, benign and malignant disorders. Many treatment options are available nowadays, including medical and conservative surgical procedures, but hysterectomy remains the most preferred method to manage gynecological disorders(2). Hysterectomy can be done by the vaginal or the abdominal route, or with laparoscopic assistance(3). This helps in adequate sampling of the required and suspected areas and thus helps in the diagnosis of various lesions without any error of sampling.

The objective of the study was to study the histopathological features of varied lesions of the uterus, their profile, and the distribution of different lesions in relation to age.

\section{MATERIALAND METHODS}

Total 448 hysterectomy specimens were received in the Department of Pathology, Government Medical College, Ananthapur, a tertiary health care centre over a period of 2 years, i.e., January 2017 to December 2018. It is a retrospective study. The information is retrieved from the records, and slides were reviewed, whenever necessary repeat sections were taken and processed.

\section{RESULTS}

A total of 448 cases were studied. The most common type of hysterectomy was total abdominal hysterectomy comprising 293 cases $(65.40 \%)$.

Table 1: Types of specimens received at Dept of Pathology GMC ATP.

\begin{tabular}{|c|c|c|c|}
\hline S.NO & TYPE OF SPECIMEN & NO.OF CASES(448) & $\mathbf{\%}$ \\
\hline $\mathbf{1}$ & SIMPLE HYSTERECTOMY & 155 & $34.60 \%$ \\
\hline $\mathbf{2}$ & $\begin{array}{c}\text { TOTAL ABDOMINAL } \\
\text { HYSTERECTOMY }\end{array}$ & 293 & $65.40 \%$ \\
\hline
\end{tabular}

The hysterectomies were distributed over a wide age range of 21 to more than 70 years. Of these, 186 cases $(41.51 \%)$ were encountered in the age group of $40-49$ years, which is the most common age group

Among endometrial lesions, Atrophic endometrium was the most common endometrial pathology seen in $24.77 \%$ cases followed by endometrial hyperplasia(10.04\%). Malignant tumors comprised only $1.56 \%$ of cases, i.e., 3 cases of endometrial adenocarcinoma and one case of endometrial stromal sarcoma were observed.

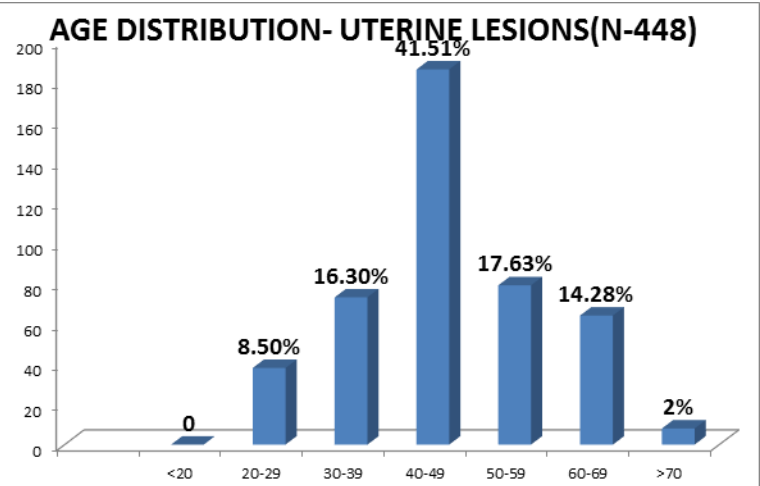

Chart 1: Bar diagram showing the Age distribution of uterine lesion.

Table No 2: Showing Histomorphological Variants Of The Endometrium

\begin{tabular}{|l|l|l|l|}
\hline $\begin{array}{l}\text { S. } \\
\text { No }\end{array}$ & ENDOMETRIAL LESIONS & $\begin{array}{l}\text { NO. OF } \\
\text { CASES(448) }\end{array}$ & \% \\
\hline 1 & PROLIFERATIVE PHASE & 127 & $28.34 \%$ \\
\hline 2 & SECRETORY PHASE & 96 & $21.42 \%$ \\
\hline 3 & DISORDERED PROLIFERATION & 23 & $5.13 \%$ \\
\hline 4 & ENDOMETRIAL HYPERPLASIA & 45 & $10.04 \%$ \\
\hline 5 & ATROPHIC ENDOMETRIUM & 111 & $24.77 \%$ \\
\hline 6 & ENDOMETRIAL POLYP & 38 & $8.48 \%$ \\
\hline 7 & ENDOMETRIAL CARCINOMA & 7 & $1.56 \%$ \\
\hline 8 & $\begin{array}{l}\text { EXTENSION OF CERVICAL } \\
\text { CARCINOMA }\end{array}$ & 1 & $0.22 \%$ \\
\hline
\end{tabular}


In most of the cases ( $51.0 \%)$, myometrium was unremarkable, showing only physiological changes. The most common myometrial pathology encountered was leiomyoma (23\%), followed by adenomyosis $(21 \%)$. In $4 \%$ of the cases, myometrial blood vessels showed monkebergsclerosis.

\section{SPECTRUM OF MYOMETRIAL LESIONS} $(\mathrm{N}=448)$

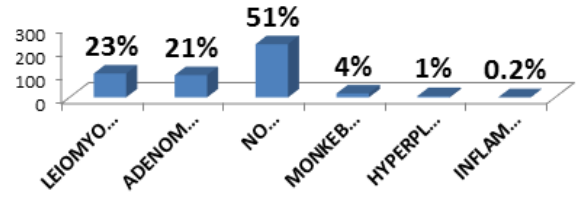

Chart no:2 Bar diagram showing the distribution of myometrial lesions

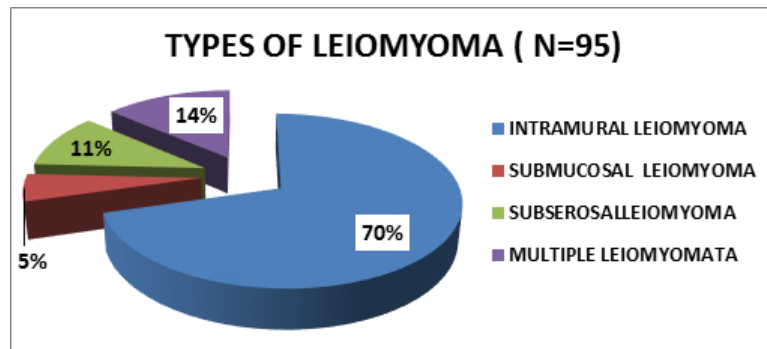

Chart no:3 Pie diagram showing various types of leiomyoma
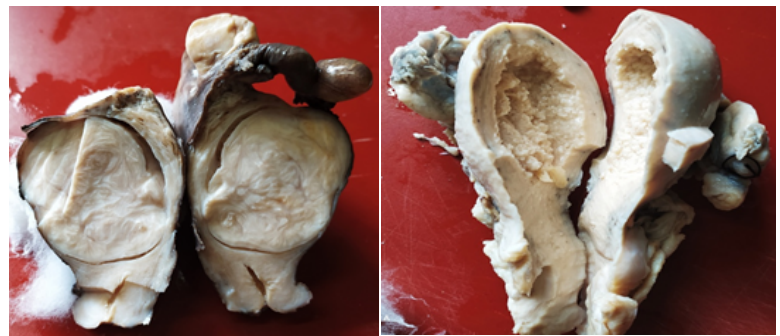

Fig1: Gross specimen showing Fig:2 Gross specimen showing submucosal leiomyoma

endometrial carcinoma

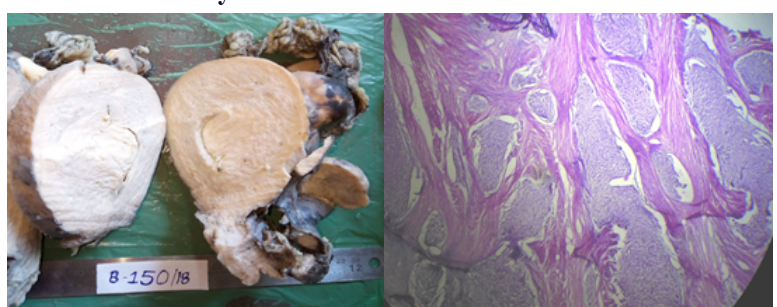

Fig 3:Gross specimen showing Fig 4: Endometrial stromal endometrial stromal sarcoma sarcoma invading into myometrium H\&E 10x

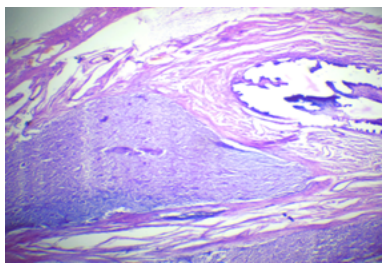

Fig 3:Endometrial stromal sarcoma metastasizing to fallopian tube $\mathrm{H} \& \mathrm{E} \mathbf{4 X}$

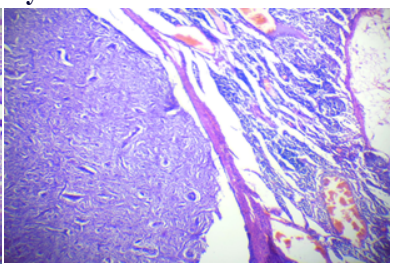

Fig 4: Endometrial stromal sarcoma metastasiSing to lymph nodes $\mathrm{H} \& \mathrm{E} 10 \mathrm{x}$

\section{DISCUSSION:}

Hysterectomy is the most commonly performed major gynecological surgery throughout the world. It is a successful operation in terms of symptom relief and patient satisfaction and provides definitive cure to many diseases involving uterus as well as adnexa.(4). This study was conducted to analyze the patterns of lesions in hysterectomy specimens in our institution and correlate the findings of other workers. In the present study, the maximum number of patients i.e., is $41.51 \%$, was seen in the age group of the $5^{\text {th }}$ decade. In an analysis of
1000 consecutive operations by Watts et al. (5), the most number of cases, i.e., $45.2 \%$, were distributed in the age group of the $5^{\text {th }}$ decade. Various studies done by Rather GR et al. (6), Ramchandran T et al. (7), and Ajmera et al. (8) had similar findings.

The most common surgical approach in the present study is abdominal hysterectomy (65.4\%). A study by Ajmera et al. (8) abdominal approach was preferred in $54.4 \%$ cases. In the present study, $45(10.04 \%)$ cases of endometrial hyperplasia were noted. All are simple hyperplasia without atypia. This finding was comparable with the studies done by Ojeda V (9). and Ranabhat et al. (10), which showed $22.3 \%$ and $16 \%$ of cases of endometrial hyperplasia, respectively. Three cases $(1.56 \%)$ of endometrial carcinoma were noted in the age group of above 45 years in our study. One case of stromal sarcoma in a patient of age $26 y$ rs was noted. The patient had metastasis in both fallopian tubes, both ovaries, and lymph nodes. Endometrial stromal sarcoma is a rare tumor comprising $0.2 \%$ of all uterine malignancies, $<10 \%$ of cases of uterine sarcomas. The mean age is 42 to 58 years. Local recurrences and distant metastasis are frequent. Leiomyoma is the most common $(23 \%)$ myometrial lesion in this study. Most of the studies done on the histopathological examination of hysterectomy specimen to date reveal uterine fibroid are the most common pathology noted in the uterus. Studies were done by Watts WF et al (5) Abdullah LS(11), and Ranabhat SK et al(10) had the distribution of fibroid being $41.5 \%, 34.6 \%$, and $30.3 \%$ respectively. Adenomyosis is the second most common myometrial pathology in this study. Adenomyosis( $21 \%$ )is rarely diagnosed preoperatively and is still largely under-diagnosed as it has no specific symptoms of its own( 12). It is usually diagnosed after hysterectomy by histopathological examination( 13). we have noted a case of squamous cell carcinoma of cervix extending to the endometrial cavity.

\section{CONCLUSION:}

Hysterectomy is the most common surgery performed in gynecological practice. A wide range of lesions are noted when hysterectomy specimens are subjected to histopathological examination.

\section{REFERENCES}

Ellenson LH, Pirog EC. The female genital tract.In: Kumar V, Abbas AK, Fausto N, Aster JC.Robbins and Cotran Pathologic basis of disease.8th ed. Philadelphia: Elsevier 2010;.1005-1063

2. Qamar-Ur-Nisa. Habibullah.Shaikh TA, Hemlat, Memon F, Memon Z.Hysterectomies; An audit at a tertiary care hospital. Professional Med J.2011 Mar; 18(1):46-50

Silverberg SG, DeLellis RA, Frable WJ, LiVolsi VA, Wick MR. Silverberg's Principles and practice of surgical pathology and cytopathology. 4 th . Edinhur Analysis of 1000 consecutive operations. Obstet Gynecol. 1956,May; 7(5)483-93.

4. Jaleel R, Khan A, Soomro N. Clinicopathological study of abdominal hysterectomies. Pak J Med Sci 2009; 25 (4): 630-34

Watts WF, Kimbrough RA. Hysterectomy Analysis of 1000 consecutive operations Obstet Gynecol. 1956,May; 7(5)483-93.

6. Rather GR, Gupta Y, Bardhwaj S.Patterns of Lesions in Hysterectomy Specimens: A prospective study. JK Sci J Med Edu Res.2013Apr-Jun: 15(2):63-68. [Available from wwww.jkscience. org].

Ramachandran T, Sinha P, Subramanium. Correlation between Clinicopathological and Ultrasonographical Findings in Hysterectomy. Journal of Clinical and Diagnostic Research 2011,Aug:5(4):737-740

8. Ajmera Sachin K, Mettler L, and Jonat W. Operative spectrum of hysterectomy in German university hospital. J Obstet Gynecol India. 2006;56(1):59-63.

9. Ojeda VJ. The pathology of hysterectomy specimens. Z Med J. 1979; 89(631): 169$71 ; 1(1)$

10. Ranabhat SK. Shrestha R. Tiwari M, Sinha DP. Subedee LR. A retrospective histopathological study of gysterectomy with or without salpingo-oophorectomy specimens, JCMC. 2010

11. Abdullah LS. Hysterectomy: A clinicopathologic correlation> Baharain Medial Bull Weiss G, Maseelall P, Schott LL, Brockwell SE, Schocken M, Johnston JM. Adenomyosis a variant, not a disease? Evidence from hysterectomies menopausal Adenomyosis a variant, not a disease? Evidence from hysterectomies menopausal 91 (1): 201-6.

12. Mehboob R, Ahmad N. Unexpected pathology at vaginal hysterectomy for genital prolapse. Pak J Med Res 2002; 41 (4): 142-4

13. Shrestha A, Shrestha R, Sedhai LB, Pandit U. Adenomyosis at hysterectomy: prevalence, patient characteristics, clinical profile, and histopathological findings. Kathmandu Univ Med J 2012;37 (1):53-56 